\title{
In the Name of Prevention: Maternal Perspectives on School-Based HPV Vaccination in Rural Southern Chile
}

\author{
Ryan Arams' \\ Rachel E Weinstock (D) ${ }^{2}$ \\ Emma Satterthwaite Muresianu ${ }^{2}$ \\ Stasha O'Callaghan ${ }^{3}$ \\ Elizabeth Tubridy ${ }^{4}$ \\ Yumarlin Torres Maita ${ }^{5}$ \\ Siobhan M Dolan (1D ${ }^{6}$ \\ 'Family Medicine Residency, Ventura \\ County Medical Center, Ventura, CA, \\ USA; ${ }^{2}$ Department of Obstetrics and \\ Gynecology, Albert Einstein College of \\ Medicine (AECOM), Bronx, NY, USA; \\ ${ }^{3}$ Emergency Medicine Residency, NYU \\ Langone Health/Bellevue Hospital \\ Center, New York, NY, USA; ${ }^{4}$ Obstetrics \\ and Gynecology Residency, NYU \\ Langone Health, New York, NY, USA; \\ ${ }^{5}$ Department of Child and Adolescent \\ Obstetrics and Gynecology, Hospital de \\ Linares,Universidad Autónoma De Chile \\ (UA), Talca, Chile; ${ }^{6}$ Division of Genetics \\ and Genomics, Department of \\ Obstetrics, Gynecology, and \\ Reproductive Science, Icahn School of \\ Medicine at Mount Sinai, New York, \\ NY, USA
}

Purpose: Since the introduction of the HPV vaccine in Chile in 2014, there have been few studies exploring community perspectives on the vaccine, specifically of parents of adolescents. This study sought to identify maternal factors and family dynamics that affect HPV vaccination behavior.

Participants and Methods: Participants were recruited at an $\mathrm{OB} / \mathrm{GYN}$ clinic in Linares, Chile. Participation was voluntary, and eligibility required 1) having an adolescent daughter between 9 and19 years-old and 2) demonstrating a willingness to discuss HPV-related topics. Thirty semi-structured interviews were conducted to generate qualitative data analyzed using Grounded Theory methodology.

Results: Three thematic constructs emerged from the interviews. Mothers' motivations to vaccinate centered on disease prevention and trust in the medical system but were influenced by notions of sexual liberalism and promiscuity. Second, participants desired, but often had trouble finding, adequate information about vaccine safety and turned to the internet. Third, joint decision making in the family about vaccination led to open family discussions about sex and sexuality.

Conclusion: Chile's school-based opt-out HPV vaccination program engenders a unique landscape of maternal decision-making, risk-benefit analysis, information-seeking, and athome discussion. More studies are needed around the variable role of fathers in the decisionmaking process.

Keywords: Latin America, reproductive health, preventative care, adolescents

\section{Plain Language Summary}

In 2014, Chile introduced an opt-out school-based vaccination program for girls against the human papillomavirus. To date, very few studies have been published on community perspectives of the vaccine. Our team was curious about the maternal perspective about the HPV vaccine and the school-based program, and how they made the decision to vaccinate (or not) their adolescent daughters. We interviewed 30 participants and analyzed the interview text for common themes to our questions. Generally, mothers trusted the vaccine because they trusted the medical system. They spoke about wanting more information from trusted sources and reported searching online for answers to their questions about the vaccine. Mothers noted that talking about the HPV vaccine at home opened up discussions with their daughters and partners about sex, as well as reflected commonly-held notions of gender roles. These data can be used to inform future vaccination efforts in Chile and other middle-income countries with school-based vaccination programs.
Correspondence: Siobhan M Dolan Division of Genetics and Genomics, Department of Obstetrics, Gynecology, and Reproductive Science, Icahn School of Medicine at Mount Sinai, I I 76 Fifth Avenue, 9th Floor, Box II70, New York, NY, 10029, USA

Tel + I 212 24I-9746

Email siobhan.dolan@mssm.edu 


\section{Introduction}

Cervical cancer is the third leading cause of cancer-related death for women in South America. ${ }^{1}$ Cervical cancer is widely regarded as preventable due to the availability of papanicolaou tests (pap smears) and vaccines against the human papillomavirus (HPV), a sexually transmitted infection. HPV has over 200 serotypes and while most infections resolve on their own, certain strains may cause the development of genital warts, invasive cervical cancer, and some head and neck cancers.

HPV prevention campaigns have existed for some time and vary widely, highlighting the need for investigation regarding barriers to vaccination as well as areas of success. For example, Australia implemented a primarily school-based nationwide HPV vaccine campaign in 2007 for females, adding males in 2013, between ages 12-13. As of 2017 , this program reports uptake rates of $80.2 \%$ and $75.9 \%$ coverage of eligible teens under 15 years of age. $^{2}$ On the other hand, the United States introduced the HPV vaccine as a non-mandatory clinic-based program in 2008 for females and 2011 for males ages 11-12. As of 2018 only $39.9 \%$ of adolescents aged $13-17$ are up-to-date with this vaccine. ${ }^{3}$ Similarly, across the Andean region there is variability in HPV vaccination strategies, with Chile being one of the countries with a mandatory schoolbased campaign. ${ }^{4}$

Chile has the lowest HPV-related cancer incidence and mortality rate in the Andean region of Latin America. ${ }^{1,5,6}$ After the government bolstered pap smear availability in the late $1980 \mathrm{~s}$, the cervical cancer mortality rate dropped from 14.3 to 8.5 per 100,000 women over the subsequent decade. ${ }^{7}$ Cervical cancer screening, diagnostics and treatment are covered by the public health insurance infrastructure. ${ }^{8}$ Despite this coverage, pap smear programs reach only $50-55 \%$ of Chilean women. Cervical cancer remains the second most prevalent malignancy in Chilean women ages $15-44 .^{9}$ Therefore, a wide-reaching schoolbased vaccination program offers an additional preventative measure against this national cancer burden.

In 2014, the Chilean Ministry of Health incorporated the human papillomavirus quadrivalent HPV-6/-11/-16/-18 vaccination (Gardasil ${ }^{\circledR}$ ) into the National Immunization Program. ${ }^{10}$ The Ministry added the vaccine to a list of opt out "obligatory" immunizations, administering them at schools in two doses, 12 months apart, free of charge. Initially the vaccine was only available to females in 4 th and 5th grade (ages 9-11), but in 2015 coverage expanded to girls in 7th grade (up to age 14) ${ }^{11}$ In 2018, when our study was conducted, the Ministry reported $87 \%$ coverage of 1 st dose in the 4 th grade and $76 \%$ coverage of the 2 nd dose in 5 th grade nationwide, with the Region de Maule having one of the highest coverage rates at $94 \%$ for the 1 st dose and $87 \%$ for the 2nd dose. Additional school-based vaccinations include DTaP in 1st and 8th grade and MMR in 1st grade, all of which have higher overall rates of coverage compared to the HPV vaccine. ${ }^{12}$ In 2019, after our study was conducted, the Ministry then approved the vaccine for adolescent boys of the same ages. ${ }^{13,14}$

The medical literature has not yet explored whether societal attitudes and perceptions of the vaccination may help explain the coverage gaps or regional variation in uptake. Nor do any studies represent the Chilean perspective on HPV vaccination after it became free and mandated in 2014. A 2017 literature review of HPV vaccination research in the Andean Region found only 5 studies related to Chile, ${ }^{5}$ all data collected prior to 2014 : these include studies of disease burden, vaccine cost, and one of adolescent HPV knowledge. Additionally, a 2020 literature review on barriers to childhood vaccinations in Latin America, found a single study on Chilean parents' perceptions of vaccines overall and not the HPV vaccine specifically. ${ }^{15}$ We focused the current study on mothers of adolescents in Chile, as previous explorations of Chilean parental attitudes on childhood vaccination focused mainly on mothers and would allow easier contextualization of findings. ${ }^{16}$ Moreover, the purpose of this qualitative study is to explore maternal perspectives on HPV vaccination and adjacent sexual health topics, in the context of a costfree nationalized school-based campaign in Linares, Chile. The specific objectives of this effort were:

1. Understand the maternal decision-making process around HPV vaccine administration for their adolescent daughters.

2. Explore participants' current knowledge of cervical cancer, HPV, and the vaccine.

3. Identify the sources of that knowledge.

4. Identify strategies to promote increased access to HPV vaccination.

\section{Participants and Methods}

This study was approved by both a US-based allopathic medical school Institutional-review board and the local Chilean Department of Health's Committee of Science Ethics, with support from a Chilean medical school. 
A qualitative semi-structured interview format best captured a range of responses and allowed for open discussion of mothers' decision-making processes. Our semi-structured questionnaire was designed with face and content validation conducted by local regional cultural experts, physicians and medical students with attention to local concerns. Researchers predicted that a sample size of 30 participants should achieve saturation, as several texts on grounded theory methodology suggest selecting sample sizes ranging from 20-50, with the average at $31 .{ }^{17}$ A convenience sample of thirty women participated from an ambulatory $\mathrm{OB} / \mathrm{GYN}$ clinic in Linares, Región de Maule, Chile between February and March 2018. This region was chosen as the location of the study as a result of the long-standing relationship with a Chilean medical school, which is located in the region and is affiliated with the clinic in Linares. Per the 2017 Census, $26.8 \%$ of the population in the Region de Maule lives rurally, more than double the percentage of the population living rurally in Chile nationally $(12.2 \%) .{ }^{18}$

Recruitment, informed consent, and interviews were conducted in Spanish by senior medical students who traveled to Chile for an international rotation during medical school. Each student had advanced to non-native fluent Spanish skills. Participation was voluntary without additional incentive. Entry criteria were mothers who had 1) at least one adolescent daughter between ages 9-19 and 2) demonstrated a willingness to discuss HPV-related illness and vaccination. Prior to interviewing, participants read informed consent documents and received a copy of the forms signed by both investigator and participant.

Before each interview, demographic data were collected using a structured verbal questionnaire (Figure 1). Previous studies have shown that HPV vaccine access has varied by socioeconomic status, including rural versus city residence and education level. ${ }^{19}$ Each face-to-face interview occurred in a private clinic room, lasted 10-20 minutes and was audio-recorded on a device dedicated to the project.

The team members were trained in methods of semistructured interviewing, as well as lived and worked in the community during the course of research. ${ }^{20}$ Interview audio files were uploaded to a password-protected computer and assigned study numbers. The US-based team transcribed audio files verbatim in Spanish and the Chile-based team reviewed each to ensure accuracy. Transcripts were analyzed with grounded theory independently by three members of the US-based team blinded to each other's' codes, through Dedoose, a web-based application for qualitative data analysis. ${ }^{21}$ Using a grounded theory approach, the team then agreed upon a combined list of 49 repeating ideas identified in at least 2 or more interviews then sorted into 12 themes. The themes were then organized into three major theoretical constructs, discussed subsequently in the results section. The theoretical constructs were reviewed in Chile with a consultant group of 5 female healthcare professionals during a 90-minute focus group.

\section{Results}

The participants in this study had an average age of 39 years and were geographically and educationally diverse (Table 1). All thirty interviews were analyzed with variations in vaccine uptake. Twenty-three women reported their daughters were vaccinated via the school-based program. One mother opted out of the school-based program; one mother was unaware of her daughter's vaccination status; two participants had 9-year-old daughters whose schools had not yet vaccinated for the semester, and three women had daughters outside of the HPV campaign. Interviews did not elucidate whether or not daughters received both vaccine doses. Uptake in this sample was $92 \%$ among age eligible daughters, similar to regional statistics in Maule in 2018. ${ }^{12}$

Three major theoretical constructs emerged from analysis of our themes. First, mothers' motivations to vaccinate centered on general disease prevention and trust in the medical system but were influenced by perceptions of sexual liberation and promiscuity. Explicit connection of HPV to cervical cancer, however, varied. Second, mothers desired more information about vaccine safety from professional sources and used the internet to supplement their knowledge. Finally, HPV vaccination campaign highlighted shifting roles of parents in a modern-day Chile, where familial relationships were strengthened by open discussions about sex and sexuality.

\section{Motivations to Vaccinate: "For the Health of My Daughter" in a "Sexually Liberal" Landscape}

When mothers decided to vaccinate their daughters against HPV, they justified their confidence in these vaccinations by noting their trust in the public health system at large in having their daughters' best health interests in mind.

"I have always had this mentality: that I have confidence in the health system that it will do best for our wellbeing ... In reality, I know that everything is done with an interest in health. - age 36 
When asked about whether she had any doubts about the HPV vaccine upon signing the permission slip, this same participant noted,

"In reality, no, no. I signed it and didn't think about it because you always have our health system." - Age 36

Others explicitly spoke of the prevention of cervical cancer, especially in the context of family or personal experience with cervical cancer.

"I've always been very diligent about this topic because we come from a family that has had pre-cancer, and so we want to prevent the disease." - age 32

"I found out that [cervical cancer] was a terrible disease because I lived through it personally, through my sister. It was horrible to see her, because she got to a really severe state, she died because of [her] cancer [...] she had a horrendous death, almost a year spent laid up in bed. The doctors did everything possible, they had her on many medications for months, but it was not enough [...] So, I know what it is because of that situation, it's horrible. So if there is the possibility to do a pap smear every year and a way to prevent it, I think it's ideal to avoid all the suffering that is possible with this disease." - Age 31

The motivation to vaccinate proved to be more complex than prevention alone. Mothers shared the larger context of their decision-making process, which involved a discussion of sexual promiscuity and contemporary sexual practices of teenagers. Several mothers, including those who had their daughter vaccinated, mentioned a common belief that HPV is caused by promiscuity.

"I heard them say that [HPV] is a prostitute disease. At least that's what they say here. In reality, when someone had this disease, you would wonder 'what work do they do?' because they were actually a prostitute. It was prejudiced, and people since then have started to say 'it's not that way. It was simply being sexually liberal.' Because of that, yes, women would contract it from a partner who was their husband. Or used to be their husband, I don't know." - age 38

"For example, the human papilloma virus, which someone gets when they are a teenager or something like that, because what is happening these days is that the youth are having sex at such a young age, therefore [vaccinating

How has your personal experience been with pap smears?

Have you heard of HPV? What do you know about human papillomavirus? Have you heard of the vaccine against HPV offered to girls in the 4th grade? How did you hear about it? Did you know that it's free?

Has your daughter been vaccinated against HPV? If yes, why? If not, why not?

Do you talk with your partner about the reproductive health of your children? Who makes healthcare decisions about vaccines and STD prevention in your children?

Do you generally adhere to recommendations made by your doctor or matrona? If yes, why? If not, why not?

Figure I The semi structured questionnaire. 
Table I Main Characteristics of Participants

\begin{tabular}{|l|l|}
\hline Variables & $\mathbf{n = 3 0 ( \% )}$ \\
\hline Average Age in Years (Range) & $39(26-55)$ \\
$20-29$ years & $2(7 \%)$ \\
$30-39$ years & $17(57 \%)$ \\
$40-49$ years & $7(23 \%)$ \\
$50-59$ years & $4(13 \%)$ \\
\hline Residence & \\
Rural & $16(53 \%)$ \\
Urban & $14(47 \%)$ \\
\hline Level of Education & \\
Incomplete K-8 & $2(7 \%)$ \\
Complete K-8 & $12(40 \%)$ \\
Incomplete High school & $3(10 \%)$ \\
Complete High School & $10(33 \%)$ \\
Incomplete University & $1(3 \%)$ \\
Completed University & $2(7 \%)$ \\
\hline Average Number of Living Children (Range) & $2.3(1-5)$ \\
I & $4(13 \%)$ \\
2 & $17(57 \%)$ \\
3 & $7(24 \%)$ \\
4 & $1(3 \%)$ \\
5 & $1(3 \%)$ \\
\hline Average age of Daughter in Years (Range) & $12.9(9-17)$ \\
$9-11$ & $11(37 \%)$ \\
I2-14 & $8(27 \%)$ \\
No-17 Answer & $10(33 \%)$ \\
\hline History of having had pap smear & $1(3 \%)$ \\
\hline
\end{tabular}

is] to really avoid getting this and other viruses, and all the infections they produce." - age 31

\section{"Informed" Decision Making: From Schools to the Internet, from Informed to Misinformed}

Many mothers spoke to the importance of being sufficiently informed. They noted receiving information schools, health professions, community members, television, and the internet. While some mothers cited information from schools and healthcare professionals to be sufficient, others felt this information was inadequate and turned to the internet for supplementation.

First, many mothers weighed this decision as important enough to research.

"You have to inform yourself through television, radio, newspaper, magazine, or talk to someone, you have to approach this conversational topic. When the topic is important, talk about it." -age 54 .

Second, several mothers found the Ministry's information distributed through schools to be sufficient to make the decision to vaccinate. Others derived comfort in receiving additional information about the vaccine from the healthcare workforce.

"[The information from the school] was sufficient because it was specific and clear. They explained what the vaccine is for. Yes, it was good information. I understood and I signed the authorization because I now know that the vaccine is essential for my daughter." -age 31.

"Realistically, I have noticed that the truth is best approached with someone who has studied it. There are many things that can capture your attention but they're not true." - age 39

However, not all participants saw school-based information as reliable. Some found this information lacking in regard to side effects, leading to doubt and reluctance to comply. While they ultimately consented to vaccination, this doubt shaped their decision into one of risks versus benefits.

"I would like to know more. I think more information about the vaccine is missing like what it contains, the side effects, the probabilities ... because some girls can have fever, others get a cold, some cannot even touch their arm afterwards. [...] I would have liked to have had more information about that." -age 35

"There are always pros and cons with these things. People say 'no' to the vaccine because they're injecting something that isn't good for your body, but afterwards they come to you and say 'No, it is good'. So, you're always left with this doubt. They had us send in a little paper, they told us 'yeah! We're going to vaccinate your daughter!' but they didn't actually tell us what it was for. The truth is that I wasn't going to vaccinate her because of that doubt. But after I said, 'I'll vaccinate her in the name of prevention' - age 26

Moreover, to supplement information given by healthcare personnel, and to verify commentary from other community members, mothers often used the internet. They spoke to how this directly influenced their decision, whether to ultimately decide to vaccinate or, in the case of one mother, to opt out. 
"They talked about the vaccine in a class meeting. Present in the meeting were moms that disagreed with the vaccine because of this and that ... For example, a mom said, 'it's not that the vaccine gives the girls fevers, the vaccine sterilizes them.' I started to use the internet to ask other people to verify. They said, "The risks of the vaccine were not significant.' So, I chose to vaccinate her." - age 37

"I just typed it [into Google] exactly as I would ask it because an answer always comes out. 'Secondary effects of the HPV vaccine.' And out came a lot of information with everything that I'm telling you right now. That in Asia and Europe they're prohibiting the vaccine, I think they banned it in Japan too, things like that." - age 44, who opted-out of the vaccine for her daughter

\section{Family Decisions: Open Discussions on Sex, Wide Gaps in Gender}

There was more to the decision than the science, the media messages, and anecdotal observations. Family discussions were key to decision making. For some women, these discussions offered a launching point for at-home sex education. For others, discussions about HPV vaccination reinforced stereotypical gender roles.

Approximately half of the mothers shared the decisionmaking process with the father of the adolescent. Talks often led to open conversations regarding safe sex, fostering trust between parents and daughter.

"Yes, we decided together. Because we approached the topic together, we looked at the pros and cons. In the end, the pros were more than the cons, and we chose to vaccinate her." - age 26

"We have been very open with them, we converse with them about everything, everything. Also, she gets along well with my husband. He tells her stuff because, like he says, he doesn't want her to make the same mistakes that we made." - age 41

"I am super open-minded. I prefer that she confides in me if she's going to [have sexual relations], to prevent that she does it in secret. This way, if in the end she does [has sex], I don't have to be at her pillow yelling 'No! No!'” -age 38

"At that moment, I spoke with her. She told me that she didn't want to receive the vaccine. But I explained to her a little about it. In that moment I spoke with her about how I had had HPV. So, she decided 'yes."' - age 38

About half of the mothers did not share the decision with the father. Some women utilized the word "machista" to describe the attitude among their partners that decisions around a daughter's sexual health are strictly obligations of mother. This word was also used when fathers denied the sexual lives of their children.

'He says, 'I am the man and you are the mother.' You know, in that way. Because I am the mother. He says, 'Because I am a man, I don't know these things!'” - age 39

'He doesn't agree with me [about the vaccine], but, as a woman I have to teach our daughter that she has to protect herself. He is older than I am and a little machista. He thinks his daughter will never date. He shelters her a lot so doesn't think she has to prevent anything." - age 35

Nevertheless, while not directly invoking "machismo" or "gender roles," other women who made the decision alone also cited separate responsibilities in their relationship with the father,

"He works and works and works. I always take on the responsibility of their health. I go with them to their appointments. It's not that their health is more important to me than to him. He's always thinking about them. 'Is she sick? Does she have a headache?' But it's always me who cares for her. Why? Because of his job, he cannot." age 54

"I was married for a long time, so my three children are from the same father. But he found another person and left us. We coexist well as parents, but we haven't been together for a long-time now. So, yes, practically, when decisions have to do with the kids, I make those decisions." -age 37

\section{Discussion}

Our study is the first to investigate motivations of Chilean mothers regarding HPV vaccination for their adolescent daughters. This work highlights the key attitudes and perceptions shared among mothers that may contribute to Chile's, and the Maule Region's, relatively high uptake of HPV vaccination. ${ }^{9,12,22}$ By exploring the lived experiences of these mothers, we highlight the potential impact of a cost-free, opt-out school-based HPV vaccination program in Chile, which may have implications for other countries regionally and globally.

Mothers considered prevention of illness, in general and in their own daughter, as a primary motivating factor to vaccinate. Not all mothers explicitly acknowledged that the HPV vaccine prevents cervical cancer. However, mothers who experienced HPV-related disease themselves 
or in family, friends, or neighbors emphasized the connection between the vaccine, cervical cancer, and a sense of parental duty to protect their daughters from similar suffering. In addition, trust in the Chilean healthcare system gave most participants confidence in the vaccine: the HPV vaccination appeared to qualify as necessary for their daughters as they believe the government public efforts have the best interest of their children in mind. Their confidence in Chilean healthcare contrasts with the lack of confidence cited as a barrier to general vaccine acceptance in other Latin American populations. ${ }^{5,23}$ This is a critical finding, as the success of a school-based nationalized program for vaccination likely finds its success in the already-established trust in larger public infrastructure.

Stigma around HPV and promiscuity complicated mothers' desire to vaccinate and prevent disease, even in mothers who ultimately had their daughter vaccinated. Many mothers articulated the prevalent idea that only promiscuous women get HPV infections. The Chilean public health system attempts to address this misconception: one of the "Frequently-Asked Questions" on the Chilean government website about the HPV vaccine is, "If my child is not promiscuous, why does she need the vaccine?"24 Other regional studies illustrate a similar parental fear that administering the HPV-vaccine will induce promiscuity amongst adolescent girls by giving a false sense of protection against all sexually-transmitted infections. ${ }^{19,25}$ These fears are incongruous with the scientific community's findings: HPV vaccination status does not influence indicators of increased sexual activities including rates of STIs and adolescent pregnancy. ${ }^{26,27}$ This common incongruity illustrates a continual friction between epidemiological findings and community stereotypes. Even in this study's sample of women, $100 \%$ of whom have had pap smears, some of whom have had HPV-related pathologies themselves, these stereotypes are notably present. However, these opinions may be changing. For example, one mother described her community's understanding of HPV and sexual activity as changing: from "a prostitute's disease" to one of "sexual liberalism." To encourage mothers to vaccinate their daughters against HPV, messaging may need to come hand-in-hand with non-stigmatized recognition of sexually liberal behavior. Another tactic, as recommended by the American Academy of Pediatrics, is to move away from a risk-based vaccine recommendation to an earlier agebased recommendation to destigmatize HPV vaccination. ${ }^{28,29}$
Mothers in this study performed informed risk-benefit analyses as an important step in deciding whether or not to vaccinate. The doctor, matrona, and school were often trusted sources of information for such analyses. However, there remained a demand for addressing concerns about potential vaccine side effects, especially when the schools did not seem to mention even minor adverse experiences. Both international clinical trials and Latin American-specific reviews confirm that minor side effects are possible but are often limited to injection site pain or erythema. $^{30,31}$ Validated information about side effects must be a focus of parent education.

Many mothers turned to the internet for their lingering questions about side effects, which had mixed outcomes. Some found the information on the internet clarified any misunderstandings about vaccine side effects and as result, supported their decision to vaccinate. However, one participant found debunked studies from other countries on vaccine side effects and cited her search as rationale to opt out of vaccination. A 2017 study compared available information about HPV vaccination on Spanish Wikipedia, Spanish Yahoo Answers, and the Chilean Ministry of Health's website, and found that Wikipedia was largely accurate and reliable. ${ }^{32}$ The same study found that the government website lacked information about how the vaccine works. A health-conscious population of mothers such as the one in this study, craves more depth of information. As several participants noted, however, school-based information sessions and materials are likely insufficient to address concerns and rumors about the vaccine. Because of this, schools and healthcare should recommend trusted third-party sources on the internet.

Interestingly, several parents enthusiastically used the topic of HPV vaccination to launch sex-education in the household. Mothers' reflections conveyed tensions in family structure and gender expectations. While some fathers readily participated in sex-ed conversations, other fathers did not. Lack of paternal involvement was attributed to time constraints, child custody, paternal disapproval, or the perception that sex-education is a mother's role. If the father did not approve of home sex-education or felt this was the mother's role then the mother described the father as machisto. Machismo has been described as a traditional model of gender role socialization where men have explicit power over women, with resulting cognitive, emotional, and behavioral effects. ${ }^{33-35}$ While machismo is slowly changing, some mothers reflected that home sex- 
education persists as a gendered responsibility amongst parents in Chile.

This study reveals variability in the familial decisionmaking process around HPV vaccination. How individual families navigate gender roles and sexual health decisionmaking is a question that practitioners can investigate on a case-by-case basis. Beyond the clinic, HPV campaign messages can include the power of family discussions as a positive outcome of sharing the decision of vaccination between parents and children. Moreover, studies exploring the additional perspectives of fathers of adolescents on the HPV vaccine and sex education in the home will help to better elucidate and then address the role of machismo. Exploring the school-based vaccination program uncovered the nature of at-home discussions about sex and gender and provides opportunities for new research questions.

\section{Limitations}

Selection bias towards reproductive health-conscientious participants is a likely limitation in this study's applicability toward informing wider vaccination campaign strategies. Participants were recruited from a waiting room in a gynecology outpatient setting. As such, their values of prevention or trust in the medical system may be biased in a positive direction. Similarly, our questionnaire was based on local provider input and previous study work in the same clinic, thereby possibly limiting generalizability of our findings to other regions and settings. Finally, these interviews only lasted 20 minutes which may have narrowed the perspectives we gained from our participants. For example, discussions around the content of family conversations around sex and HPV were limited and will be addressed in subsequent studies.

\section{Conclusion}

The scientific community worldwide understands the importance of HPV vaccine in preventing cervical cancer morbidity and mortality; however, the factors motivating mothers to vaccinate their daughters are multifaceted and sit within a complicated contextual web. This study begins to reveal what some of that context is for women in Linares, Chile where the vaccination rates were upwards of $90 \%$ at the time the study was conducted. Our findings, then, highlight potential avenues for the health infrastructure of Chile to increase vaccination rates throughout the country. First, emphasis should be placed on the HPV vaccine to prevent cervical cancer. The focus on prevention should be bolstered by health professional's emphasis on shared concern for the well-being of individual children and open discussion of the myths about HPV and promiscuity. Practitioners may assuage these myths by using an age-based approach to recommending the vaccine, like in other countries. Future studies should assess Chilean parents' explicit knowledge of HPV and cervical cancer to supplement our recommendations for future HPV vaccination campaigns. Second, mothers frequently desired supplemental information on vaccine side effects and turned to the internet for answers. We suggest that information should be disseminated within the structures that mothers already trust: schools, hospitals, and government-sponsored clinics. Official materials, especially online, should not only tell mothers to expect minor adverse effects, but also should reassure them that the sources of information claiming grave adverse effects are largely misleading. Third and finally, many mothers found that the HPV vaccine led to an open discussion about sex education more broadly with both their daughters and husbands. However, half of the mothers reflected how machismo continues to shape gender roles and inequality between parents. These results give insight into what a successful school-based mandatory HPV vaccination program might look like for other Andean and middleincome countries.

\section{Data Sharing Statement}

Data are available from the corresponding author upon reasonable request.

\section{Ethical Approval}

All procedures performed in studies involving human participants were in accordance with the ethical standards of the institutional and/or national research committee and with the Declaration of Helsinki and its later amendments or comparable ethical standards. Albert Einstein College of Medicine IRB Approval \#2018-8782; Local Chilean Health Committee of Science and Ethics Approval documents available upon request.

\section{Informed Consent}

Informed consent was obtained from all participants in the study and included publication of anonymized responses.

\section{Acknowledgments}

This study was a collaboration between Albert Einstein College of Medicine (Bronx, NY, USA) and Universidad 
Autonoma de Chile (Linares, Region de Maule, CL). First, we thank Ms. Jill Raufman and Dr. Louis Weiss at the Global Health Department for helping make travel for students possible. Second, we thank the study participants and the providers and staff at the OB/GYN clinic for their participation and help in making our study possible. Third, we thank Valeria Quetada Hernandez and Sebastian Cancino Meier, students from Universidad Autonoma de Chile who helped review our transcriptions and Dra. Encarnacion Garcia, Dra. Ivonne Moreno, Dra. Mariely Ramos, Dra Racelmy Torres, and Sra. Sandra Ixia Rodriguez Guerrero, and Sra. Viviana Jara who consulted and supported us during analysis.

\section{Funding}

Medical student researchers have received travel funding for conduction of interviews in Chile from Kuperman International Health Endowment Fund at Albert Einstein College of Medicine.

\section{Disclosure}

The authors reported no conflicts of interest for this work.

\section{References}

1. Bruni L, Albero G, Serrano B, et al. Human papillomavirus and related diseases Report in Americas. Summary Report. ICO/IARC Information Centre on HPV and Cancer (HPV Information Centre); 2019.

2. Australian government department of health. Health AGD of. Historical Human Papillomavirus (HPV) immunisation coverage rates. December 4, 2019. Available from: https://www.health.gov.au/ resources/publications/historical-human-papillomavirus-hpvimmunisation-coverage-rates. Accessed December 10, 2020

3. Walker TY, Elam-Evans LD, Yankey D. National, regional, state, and selected local area vaccination coverage among adolescents aged 13-17 years - United States, 2018. MMWR Morb Mortal Wkly Rep. 2019;68(33):68. doi:10.15585/mmwr.mm6833a2

4. Nogueira-Rodrigues A, Bukowski A, Paulino E, et al. An alert to Latin America: current human papillomavirus vaccination trends highlight key barriers to successful implementation. Cancer. 2017;123 (12):2193-2199. doi:10.1002/cncr.30647

5. Nwanodi O. Attitudes towards human papilloma virus vaccination in the latin american andean region. Healthcare (Basel). 2017;5(3) doi:10.3390/healthcare5030055

6. Capote Negrin LG. Epidemiology of cervical cancer in Latin America. Ecancermedicalscience. 2015;9:9. doi:10.3332/ecancer.2015.577

7. Enrique Donoso S, Mauricio Cuello F, Luis Villarroel P. Reducción de la mortalidad por cáncer cérvico uterino en Chile, 1990-2003 [Reduction of Mortality in Cervical Cancer in Chile, 1990-2003]. Rev Chil Obstet Ginecol. 2005;71:307-312. doi:10.4067/S071775262006000500003

8. Garantias Explicitas en Salud (GES) [Explicit Health Benefits (GES)]. Orientación en Salud. Superintendencia de Salud, Gobierno de Chile. Available from: http://www.supersalud.gob.cl/difusion/665/w3propertyvalue-1962.html. Accessed May 28, 2020.
9. Bruni L, Albero G, Serrano B, et al. Human papillomavirus and related diseases Report in Chile. Summary Report. ICO/IARC Information Centre on HPV and Cancer (HPV Information Centre); 2019.

10. Comisión Nacional de Vacunas y Estrategias de Vacunación (CAVEI). Vacuna contra el virus del papiloma humano (VPH)[Vaccine against the Human Papilloma Virus]; 2012. Available from: https://www.minsal.cl/ sites/default/files/files/VPHCAVEIRecomendacionOctubre2012.pdf. Accessed March 31, 2021.

11. Pública MDS Subsecretaría de Salud. Modifica Decreto $N^{o}$, de 2010, Que Dispone Vacunación Obligatoria Contra Enfermedades Inmunoprevenibles de la población del Pais[Modification to Decree Number 6, of 2010, Which Provides Mandatory Vaccination Against Immunopreventable Disease of the Population of the Country]; 2013. Available from: https://www.leychile.cl/Navegar?idNorma=1056598. Accessed May 28, 2020.

12. Salas MPC. Informe de Cobertura Nacional de Inmunizaciones año 2018. Ministerio de Salud de Chile, Departamento de Inmunizaciones; 2019:42.

13. Ministerio de Salud - Gobierno de Chile. Vacunación contra el Virus del Papiloma Humano[Vaccination against the Human Papilloma Virus]. Available from: https://www.minsal.cl/vacunacion-contra-elvirus-del-papiloma-humano/. Accessed May 28, 2020.

14. Ministerio de Salud - Gobierno de Chile. Autoridades de Salud inician primera vacunación en niños para prevenir el Virus del Papiloma Humano (VPH) [Health Authorities begin the first vaccinations in children to prevent the Human Papilloma Virus (HPV)]. Available from: https://www.minsal.cl/autoridades-de-salud-inician-primeravacunacion-en-ninos-para-prevenir-el-virus-del-papiloma-humano-vph 1. Accessed May 28, 2020.

15. Guzman-Holst A, DeAntonio R, Prado-Cohrs D, Juliao P. Barriers to vaccination in Latin America: a systematic literature review. Vaccine. 2020;38(3):470-481. doi:10.1016/j.vaccine.2019.10.088

16. Véliz L, Campos C, Vega P. Conocimiento yactitudes de los padres en relación ala vacunación de sus hijos [Knowledge and Attitudes of Parents in Relation to the Vaccination of their Children]. Rev Chilena Infectol. 2016;33(1):30-37. doi:10.4067/S0716-10182016000100005

17. Mason M. Sample Size and saturation in PhD Studies using qualitative interviews. Forum Qual Soc Res. 2010;11(3). doi:10.17169/fqs11.3.1428

18. Instituto National de Estadisticas, Chile. Sintesis de Resultados: censo 2017 [Summary of Results: Census 2017]. June 2018: 8. Available from: http://www.censo2017.cl/descargas/home/sintesis-de -resultados-censo2017.pdf. Accessed March 162021.

19. Wiesner C, Piñeros M, Trujillo LM. Aceptabilidad de la vacuna contra el Virus Papiloma Humano en padres de adolescentes, en Colombia. Rev Salud Publica. 2010;13.

20. Adams W. Conducting semi-structured interviews. In: Handbook of Practical Program Evaluation. 4th ed. Jossey-Bass; Wiley; 2015:492-505. doi:10.1002/9781119171386.ch19

21. Auerbach C, Silverstein L. Qualitative Data: An Introduction to Coding and Analysis. New York University; 2003.

22. Ministerio de Salud - Gobierno de Chile. Ministerio de Salud destaca coberturas de vacunación escolar durante 2017 [Ministry of Health Highlights Coverage of School Vaccination during 2017]. Available from: https://www.minsal.cl/ministerio-de-salud-destacacoberturas-de-vacunacion-de-escolar-durante-2017/. Accessed May 28, 2020.

23. Bartolini RM, Winkler JL, Penny ME, LaMontagne DS. Parental acceptance of HPV vaccine in Peru: a decision framework. PLoS One. 2012;7(10):e48017. doi:10.1371/journal.pone.0048017

24. Ministerio de Salud - Gobierno de Chile. Preguntas frecuentes sobre Vacunación contra el Virus del Papiloma Humano [Frequently Asked Questions about Vaccination Coverage against the Human Papilloma Virus]. Available from: https://www.minsal.cl/preguntas-frecuentessobre-vacunacion-contra-vph/. Accessed May 28, 2020. 
25. Fernández L, Bustos L, González L, Palma D, Villagrán J, Muñoz S. Creencias, actitudes, y conocimiento en educación sexual[Beliefs, attitudes and knowledge about sex education]. Rev Med Chil. 2000;128(6):574-583.

26. Bednarczyk RA. Human papillomavirus vaccine and sexual activity: how do we best address parent and physician concerns? JAMA Intern Med. 2015;175(4):624-625. doi:10.1001/jamainternmed.2014.7894

27. Bednarczyk RA, Davis R, Ault K, Orenstein W, Omer SB. Sexual activity-related outcomes after human papillomavirus vaccination of 11- to 12-year-olds. Pediatrics. 2012;130(5):798-805. doi:10.1542/ peds.2012-1516

28. O'Leary ST, Nyquist A-C Why AAP recommends initiating HPV vaccination as early as age 9. AAP News. December 9, 2020. Available from: https:/www.aappublications.org/news/2019/10/04/ hpv100419. Accessed December 10, 2020.

29. Saslow D, Andrews KS, Manassaram-Baptiste D, Smith RA, Fontham ETH. Human papillomavirus vaccination 2020 guideline update: American Cancer Society guideline adaptation. CA Cancer J Clin. 2020;70(4):274-280. doi:10.3322/caac.21616

30. Perez G, Lazcano-Ponce E, Hernandez-Avila M, et al. Safety, immunogenicity, and efficacy of quadrivalent human papillomavirus (types $6,11,16,18) \mathrm{L} 1$ virus-like-particle vaccine in Latin American women. Int $J$ Cancer. 2008;122(6):1311-1318. doi:10.1002/ijc. 23260
31. Vichnin M, Bonanni P, Klein NP, et al. An overview of quadrivalent human papillomavirus vaccine safety: 2006 to 2015. Pediatr Infect Dis J. 2015;34(9):983-991. doi:10.1097/INF.0000000000000793

32. Lopez CS, Krauskopf E, Villota CE, Burzio LO, Villegas JE. Cervical cancer, human papillomavirus and vaccines: assessment of the information retrieved from general knowledge websites in Chile. Public Health. 2017;148:19-24. doi:10.1016/j.puhe.2017.02.017

33. Fernández González L. Implementación de la vacunación contra el virus papiloma humano en Chile: una mirada desde los determinantes sociales de la salud "ingreso" y"género" [Implementation of vaccination against the Human Papilloma Virus in Chile; a view through the social determinants of health "income" and "gender"]. Rev Méd Chile. 2017;145(12):1605-1609. doi:10.4067/s003498872017001201605

34. Ferrer L, Cianelli R, Villegas N, et al. Exploring the masculine identity in the context of HIV prevention in Chile. J Nurs Scholarsh. 2016;48(2):128-138. doi:10.1111/jnu.12190

35. Nuñez A, González P, Talavera GA, et al. Machismo, marianismo, and negative cognitive-emotional factors: findings from the Hispanic Community Health Study/Study of Latinos Sociocultural Ancillary Study. J Lat Psychol. 2016;4(4):202-217. doi:10.1037/lat0000050
Adolescent Health, Medicine and Therapeutics

\section{Publish your work in this journal}

Adolescent Health, Medicine and Therapeutics is an international, peer-reviewed, open access journal focusing on health, pathology, and treatment issues specific to the adolescent age group. All aspects of health maintenance, preventative measures and disease treatment interventions are addressed within the journal and practitioners from

\section{Dovepress}

all disciplines are invited to submit their work as well as healthcare researchers and patient support groups. The manuscript management system is completely online and includes a very quick and fair peerreview system. Visit http://www.dovepress.com/testimonials.php to read real quotes from published authors. 